\title{
Detection of Explosives with a Fluorescent Nanofibril Film
}

\author{
Tammene Naddo, ${ }^{1}$ Yanke Che, ${ }^{1}$ Wei Zhang, ${ }^{2}$ Kaushik Balakrishnan,,${ }^{1}$ Xiaomei Yang, ${ }^{1}$ Max
} Yen, ${ }^{3}$ Jincai Zhao, ${ }^{4}$ Jeffrey S. Moore, ${ }^{*, 2}$ and Ling Zang, ${ }^{* 1}$

${ }^{1}$ Department of Chemistry and Biochemistry, Southern Illinois University, Carbondale, IL 62901;

${ }^{2}$ Departments of Chemistry and Materials Science and Engineering, 600 South Mathews Avenue, University of Illinois at Urbana-Champaign, Urbana, Illinois 61801;

${ }^{3}$ Materials Technology Center (MTC), Southern Illinois University, Carbondale, IL 62901;

${ }^{4}$ Key Laboratory of Photochemistry, Institute of Chemistry, Chinese Academy of Sciences, Beijing 100080, China.

\section{Supporting Information}

\section{Materials and general methods}

2,4-dinitrotoluene (DNT, 97\%) was purchased from Fisher, and 2,4,6-trinitrotoluene (TNT, 99\%) was from Chemservice. All other molecules and solvents (HPLC or spectroscopic grade) were purchased from Fisher or Aldrich, and used as received.

UV-vis absorption and fluorescence spectra were measured on a PerkinElmer Lambda 25 spectrophotometer and LS 55 fluorometer (equipped with a solid sample holder), respectively. AFM measurement was carried out in tapping mode on a TopoMetrix Explorer using antimony doped silicon tip. The largest scanning area is $50 \times 50 \mu \mathrm{m}$, and the highest z-resolution is about $0.2 \mathrm{~nm}$. ${ }^{1}$ TEM measurement was performed with a Hitachi 7100 (operated at $100 \mathrm{kV}$ ). The sample was prepared by drop-casting a $2.0 \mathrm{mM}$ THF solution of ACTC onto a holey carbon or silicon oxide film, followed by drying in air.

The fluorescence quenching by DNT and TNT was monitored following a similar method as previously developed in Swager lab. ${ }^{2}$ Briefly, the fluorescence spectra of the nanofibril film were measured immediately after immersing inside a sealed-jar $(50 \mathrm{~mL})$ containing small amount of the explosives (TNT or DNT). To prevent direct contact of the film with the explosives analytes, some cotton was used to cover the explosives powder deposited at the bottom of the jar. Before use the jar was sealed for overnight to achieve constant, saturated vapor pressure inside. The presence of cotton also helps maintain a constant vapor pressure.

\section{Synthesis of ACTC}

ACTC was synthesized following the protocol depicted in Scheme S1. All air or moisturesensitive manipulations were performed under argon protection using standard Schlenk techniques or in an argon filled glove box (model TS-5000 from Vacuum/Atmospheres Company). $\mathrm{CCl}_{4}$ was distilled over $\mathrm{P}_{2} \mathrm{O}_{5}$ and degassed before use. THF was distilled over $\mathrm{Na}$ before use. Analytical thin-layer chromatography (TLC) was performed on Kieselgel F-254 precoated silica gel plates. Visualization was performed with UV light $(254 \mathrm{~nm})$ or iodine stain. Flash column chromatography was conducted with silica gel 60 (230-400 mesh, $60 \AA$ ) from EM science. 
Scheme S1. Synthesis of macrocycle ACTC

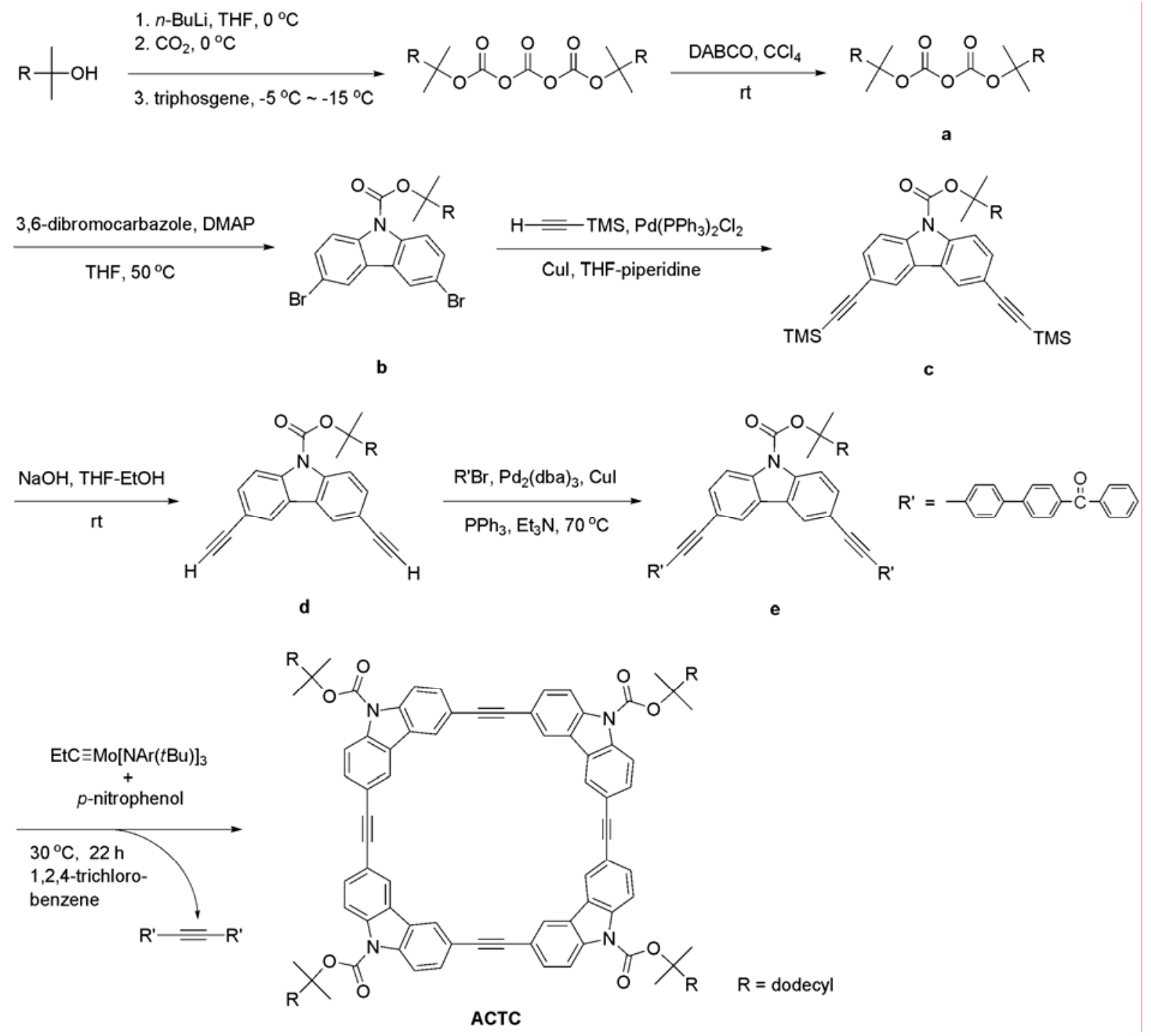

The ${ }^{1} \mathrm{H}$ and ${ }^{13} \mathrm{C}$ NMR spectra were recorded on 400 or $500 \mathrm{MHz}$ NMR spectrometers in School of Chemical Science (SCS) VOICE NMR Laboratory at the University of Illinois (http://www.scs.uiuc.edu/ mainzv/VOICE_NMR_Lab/). Proton chemical shifts are expressed in parts per million $(\delta)$ using the residual solvent protons as an internal standard. Carbon-13 chemical shifts are also expressed in parts per million $(\delta)$ using the solvent's ${ }^{13} \mathrm{C}$ resonance as an internal standard. Coupling constants $(\mathrm{J})$ are reported in Hertz $(\mathrm{Hz})$, and splitting patterns are designated as s (singlet), d (doublet), t (triplet), q (quartet), m (multiplet) and br (broad). Low and high resolution EI, FAB and MALDI mass spectra were obtained in the SCS Mass Spectrometry Facility at the University of Illinois. Elemental analyses were performed by the University of Illinois Micro Analytical Service Laboratory. Gel permeation chromatography (GPC) measurements were performed in THF at $25^{\circ} \mathrm{C}$ with a Waters 515 HPLC pump, Viscotek TDA model 300 triple detector, and a series of three Viscogel $7.8 \times 300 \mathrm{~mm}$ columns (two 
GMHXL16141 columns and one G3000HXL16136 column). Molecular weight data were determined using Viscotek's TriSEC software.

Bis(1,1-dimethyltridecyl) dicarbonate (a): ${ }^{3}$ To a solution of 2-methyl-2-tetradecanol (7.16 g, $31.4 \mathrm{mmol})^{4}$ in THF $(44 \mathrm{~mL})$ at $0{ }^{\circ} \mathrm{C}$ was added $n$-BuLi $(1.6 \mathrm{M}$ in hexane, $19.7 \mathrm{~mL})$ dropwise within $10 \mathrm{~min}$. The mixture was stirred for $40 \mathrm{~min}$ during which time it was allowed to warm up to room temperature. Then the solution was cooled down to $-5{ }^{\circ} \mathrm{C} \sim-15{ }^{\circ} \mathrm{C}$ in an ice-salt bath and a stream of anhydrous $\mathrm{CO}_{2}$ was passed through the cold reaction solution for $45 \mathrm{~min}$. When the addition of $\mathrm{CO}_{2}$ is complete, a solution of triphosgene $(2.34 \mathrm{~g}, 7.90 \mathrm{mmol})$ in benzene $(7.0 \mathrm{~mL})$ was added to the cold reaction mixture dropwise and with vigorous stirring over $20 \mathrm{~min}$, maintaining the temperature of the cooling bath at $-5{ }^{\circ} \mathrm{C} \sim-15{ }^{\circ} \mathrm{C}$. When the addition of the triphosgene solution was complete, the cold reaction mixture was stirred for additional $40 \mathrm{~min}$ while a stream of anhydrous $\mathrm{N}_{2}$ was passed through. The solvent was then removed in vacuo. To the residue was added $\mathrm{CCl}_{4}(40 \mathrm{~mL})$ at room temperature, followed by addition of DABCO $(0.043 \mathrm{~g}, 0.39 \mathrm{mmol})$, resulting in evolution of $\mathrm{CO}_{2}$. The reaction mixture was stirred at room temperature for $45 \mathrm{~min}$ before an aqueous citric acid solution $(20 \mathrm{~mL}, \mathrm{pH} \mathrm{5 \sim 6)}$ was added. The organic layer was separated, dried over $\mathrm{MgSO}_{4}$ and concentrated in vacuo at $25{ }^{\circ} \mathrm{C}$. The residue was purified by column chromatography ( $n$-hexane) affording the product as colorless oil (5.61 g, 68\%). ${ }^{1} \mathrm{H} \mathrm{NMR}\left(\mathrm{CDCl}_{3}, 500 \mathrm{MHz}\right): \delta 1.78(\mathrm{~m}, 4 \mathrm{H}), 1.52(\mathrm{~s}, 12 \mathrm{H}), 1.22-1.36(\mathrm{~m}, 40 \mathrm{H}), 0.88$ $(\mathrm{t}, J=6.7 \mathrm{~Hz}, 6 \mathrm{H}) ;{ }^{13} \mathrm{C} \mathrm{NMR}\left(\mathrm{CDCl}_{3}, 125 \mathrm{MHz}\right): \delta 146.7,89.8,40.2,31.9,29.6$ (br, signal overlap), 29.3, 25.2, 22.7, 14.1 .

3,6-Dibromocarbazole-9-carboxylic acid 1,1-dimethyltridecyl ester (b): To a solution of 3,6dibromocarbazole $(4.28 \mathrm{~g}, 13.2 \mathrm{mmol})$ and 4-N,N-dimethylaminopyridine (DMAP) (0.307 g, $2.51 \mathrm{mmol})$ in THF $(35 \mathrm{~mL})$ was added dicarbonate a $(6.60 \mathrm{~g}, 12.6 \mathrm{mmol})$ via syringe dropwise at room temperature. The resulting mixture was heated at $50{ }^{\circ} \mathrm{C}$ for $4 \mathrm{~h}$, followed by addition of diethyl ether $(50 \mathrm{~mL})$ to the cooled solution. The organic layer was washed with $\mathrm{H}_{2} \mathrm{O}(20 \mathrm{~mL})$ and brine $(20 \mathrm{~mL})$, dried over $\mathrm{MgSO}_{4}$ and concentrated in vacuo. The residue was purified by column chromatography ( $n$-hexane) affording the product as light yellow oil $(6.82 \mathrm{~g}, 94 \%) .{ }^{1} \mathrm{H}$ NMR $\left(\mathrm{CDCl}_{3}, 500 \mathrm{MHz}\right): \delta 8.14(\mathrm{~d}, J=8.6 \mathrm{~Hz}, 2 \mathrm{H}), 8.02(\mathrm{~d}, J=1.7 \mathrm{~Hz}, 2 \mathrm{H}), 7.56(\mathrm{dd}, J=8.6$, $1.8 \mathrm{~Hz}, 2 \mathrm{H}), 2.04\left[\mathrm{~m}, 2 \mathrm{H}, \mathrm{OC}\left(\mathrm{CH}_{3}\right)_{2} \mathrm{CH}_{2}\left(\mathrm{CH}_{2}\right)_{10} \mathrm{CH}_{3}\right], 1.72\left[\mathrm{~s}, 6 \mathrm{H}, \mathrm{OC}\left(\mathrm{CH}_{3}\right)_{2} \mathrm{CH}_{2}\left(\mathrm{CH}_{2}\right)_{10} \mathrm{CH}_{3}\right]$, 1.22-1.46 (m, 20H, $\left.\quad \mathrm{OC}\left(\mathrm{CH}_{3}\right)_{2} \mathrm{CH}_{2}\left(\mathrm{CH}_{2}\right)_{10} \mathrm{CH}_{3}\right], \quad 0.88 \quad(\mathrm{t}, \quad J=6.8 \mathrm{~Hz}, \quad 3 \mathrm{H}$, $\left.\mathrm{OC}\left(\mathrm{CH}_{3}\right)_{2} \mathrm{CH}_{2}\left(\mathrm{CH}_{2}\right)_{10} \mathrm{CH}_{3}\right] ;{ }^{13} \mathrm{C} \mathrm{NMR}\left(\mathrm{CDCl}_{3}, 125 \mathrm{MHz}\right): \delta 150.4$ (NCOO), 137.5, 130.5, 126.2, 122.6, 117.8, 116.3, 87.4 [OC $\left.\left(\mathrm{CH}_{3}\right)_{2} \mathrm{CH}_{2}\left(\mathrm{CH}_{2}\right)_{5} \mathrm{CH}_{3}\right]$, 40.5, 31.9, 29.8, 29.6 (br, signal overlap), 29.5, 29.4, 29.3, 26.3, 24.0, 22.7, 14.1; MS (EI): m/z (\%): 579.2 (3), 482.8 (6), 425.0 (16), 368.9 (17), 324.9 (100), 244.0 (24), 210.3 (14), 164.1 (27), 82.9 (30); HR-MS $\left(\mathrm{C}_{28} \mathrm{H}_{37} \mathrm{Br}_{2} \mathrm{NO}_{2}\right)$ : calcd 577.1212, found 577.1204; TLC $\mathrm{R}_{f}=0.26$ ( $n$-Hexane).

3,6-Bis(trimethylsilylethynyl)carbazole-9-carboxylic acid 1,1-dimethyltridecyl ester (c): Application of Sonogashira's general procedure for alkyne coupling ${ }^{5,6}$ [b (3.80 g, $\left.6.56 \mathrm{mmol}\right)$, trimethylsilylacetylene $(6.45 \mathrm{~g}, 65.6 \mathrm{mmol}), \mathrm{Pd}\left(\mathrm{PPh}_{3}\right)_{2} \mathrm{Cl}_{2}(0.276 \mathrm{~g}, 0.394 \mathrm{mmol}), \mathrm{CuI}(0.0249 \mathrm{~g}$, $0.131 \mathrm{mmol})$ in piperidine $(10 \mathrm{~mL})$ and THF $(18 \mathrm{~mL})]$ gave the product as yellow oil $(3.95 \mathrm{~g}$, 98\%). ${ }^{1} \mathrm{H}$ NMR $\left(\mathrm{CDCl}_{3}, 500 \mathrm{MHz}\right): \delta 8.19(\mathrm{~d}, J=8.6 \mathrm{~Hz}, 2 \mathrm{H}), 8.08(\mathrm{~d}, J=1.6 \mathrm{~Hz}, 2 \mathrm{H}), 7.57$ $(\mathrm{dd}, J=8.8,1.6 \mathrm{~Hz}, 2 \mathrm{H}), 2.04\left[\mathrm{~m}, 2 \mathrm{H}, \quad \mathrm{OC}\left(\mathrm{CH}_{3}\right)_{2} \mathrm{CH}_{2}\left(\mathrm{CH}_{2}\right)_{10} \mathrm{CH}_{3}\right], 1.71 \quad[\mathrm{~s}, 6 \mathrm{H}$, $\left.\mathrm{OC}\left(\mathrm{CH}_{3}\right)_{2} \mathrm{CH}_{2}\left(\mathrm{CH}_{2}\right)_{10} \mathrm{CH}_{3}\right], 1.23-1.46\left(\mathrm{~m}, 20 \mathrm{H}, \mathrm{OC}\left(\mathrm{CH}_{3}\right)_{2} \mathrm{CH}_{2}\left(\mathrm{CH}_{2}\right)_{10} \mathrm{CH}_{3}\right], 0.88(\mathrm{t}, \mathrm{J}=6.8 \mathrm{~Hz}$, $\left.3 \mathrm{H}, \mathrm{OC}\left(\mathrm{CH}_{3}\right)_{2} \mathrm{CH}_{2}\left(\mathrm{CH}_{2}\right)_{5} \mathrm{CH}_{3}\right], 0.29\left[\mathrm{~s}, 18 \mathrm{H}, \mathrm{Si}\left(\mathrm{CH}_{3}\right)_{3}\right] ;{ }^{13} \mathrm{C} \mathrm{NMR}\left(\mathrm{CDCl}_{3}, 125 \mathrm{MHz}\right): \delta 150.5$ (NCOO), 138.5, 131.2, 125.0, 123.6, 117.9, 116.1, $105.2\left[\operatorname{ArCCSi}\left(\mathrm{CH}_{3}\right)_{3}\right], 93.5\left[\mathrm{ArCCSi}\left(\mathrm{CH}_{3}\right)_{3}\right]$, 
87.3 [OC $\left(\mathrm{CH}_{3}\right)_{2} \mathrm{CH}_{2}\left(\mathrm{CH}_{2}\right)_{5} \mathrm{CH}_{3}$ ], 40.6, 31.8, 29.8, 29.6 (br, signal overlap), 29.5, 29.4, 29.3, 26.3, 24.0, 22.7, 14.1, -0.01 [Si( $\left.\left.\mathrm{CH}_{3}\right)_{3}\right]$; MS (EI): $\mathrm{m} / \mathrm{z}$ (\%): 613.4 (6), 551.3 (12), 490.3 (11), 403.2 (60), 359.2 (100), 344.2 (86), 277.1 (19), 164.7 (43), 129.1 (49), 85.1 (38); HR-MS $\left(\mathrm{C}_{38} \mathrm{H}_{55} \mathrm{Si}_{2} \mathrm{NO}_{2}\right)$ : calcd 613.3771, found 613.3771; TLC R $\mathrm{R}_{f}=0.24\left(\mathrm{CH}_{2} \mathrm{Cl}_{2} / n-\mathrm{Hexane} 1 / 9\right)$.

3,6-Diethynylcarbazole-9-carboxylic acid 1,1-dimethyltridecyl ester (d): To a solution of c $(3.94 \mathrm{~g}, 6.42 \mathrm{mmol})$, in THF $(50 \mathrm{~mL})$ and ethanol $(200 \mathrm{~mL})$ at room temperature was added a solution of sodium hydroxide $(0.521 \mathrm{~g}, 13.0 \mathrm{mmol})$ in $\mathrm{H}_{2} \mathrm{O}(7.0 \mathrm{~mL})$ dropwise within $10 \mathrm{~min}$. The resulting mixture was stirred at room temperature for $45 \mathrm{~min}$. After removing the solvent in vacuo, the residue was redissolved in $\mathrm{CH}_{2} \mathrm{Cl}_{2}(200 \mathrm{~mL})$. The organic layer was washed with $\mathrm{H}_{2} \mathrm{O}$ $(60 \mathrm{~mL})$ and brine $(60 \mathrm{~mL})$, dried over $\mathrm{MgSO}_{4}$ and concentrated in vacuo. The residue was purified by column chromatography $\left(\mathrm{CH}_{2} \mathrm{Cl}_{2} / n\right.$-Hexane 1/9) affording the product as light yellow oil (2.98 g, 99\%). ${ }^{1} \mathrm{H}$ NMR ( $\left.\mathrm{CDCl}_{3}, 500 \mathrm{MHz}\right): \delta 8.22$ (d, $\left.J=8.6 \mathrm{~Hz}, 2 \mathrm{H}\right), 8.10$ (d, $J=1.6 \mathrm{~Hz}$, $2 \mathrm{H}), \quad 7.60(\mathrm{dd}, J=8.7,1.6 \mathrm{~Hz}, 2 \mathrm{H}), 3.12(\mathrm{~s}, 2 \mathrm{H}, \operatorname{ArCCH}), 2.04[\mathrm{~m}, 2 \mathrm{H}$, $\left.\mathrm{OC}\left(\mathrm{CH}_{3}\right)_{2} \mathrm{CH}_{2}\left(\mathrm{CH}_{2}\right)_{10} \mathrm{CH}_{3}\right], \quad 1.72$ [s, $\left.6 \mathrm{H}, \quad \mathrm{OC}\left(\mathrm{CH}_{3}\right)_{2} \mathrm{CH}_{2}\left(\mathrm{CH}_{2}\right)_{10} \mathrm{CH}_{3}\right], 1.22-1.46 \quad(\mathrm{~m}, 20 \mathrm{H}$, $\left.\mathrm{OC}\left(\mathrm{CH}_{3}\right)_{2} \mathrm{CH}_{2}\left(\mathrm{CH}_{2}\right)_{10} \mathrm{CH}_{3}\right], 0.87\left(\mathrm{t}, J=6.8 \mathrm{~Hz}, 3 \mathrm{H}, \mathrm{OC}\left(\mathrm{CH}_{3}\right)_{2} \mathrm{CH}_{2}\left(\mathrm{CH}_{2}\right)_{10} \mathrm{CH}_{3}\right] ;{ }^{13} \mathrm{C} \mathrm{NMR}$ $\left(\mathrm{CDCl}_{3}, 125 \mathrm{MHz}\right): \delta 150.5$ (NCOO), 138.7, 131.4, 125.0, 123.7, 116.9, 116.3, 87.4 [OC $\left(\mathrm{CH}_{3}\right)_{2} \mathrm{CH}_{2}\left(\mathrm{CH}_{2}\right)_{5} \mathrm{CH}_{3}$ ], 83.7 [ $\mathrm{ArCCSi}\left(\mathrm{CH}_{3}\right)_{3}$ ], 76.7 [ $\mathrm{ArCCSi}\left(\mathrm{CH}_{3}\right)_{3}$ ], 40.5, 31.9, 29.8, 29.6 (br, signal overlap), 29.5, 29.4, 29.3, 26.3, 24.0, 22.7, 14.1; MS (EI): m/z (\%): 469.4 (2), 277.1 (8), 259.1 (10), 215.1 (100), 187.1 (8), 129.1 (43), 107.6 (11), 85.1 (27); HR-MS $\left(\mathrm{C}_{32} \mathrm{H}_{39} \mathrm{NO}_{2}\right)$ : calcd 469.2954, found 469.2959; TLC $\mathrm{R}_{f}=0.50$ (EtOAc/n-Hexane 1/19).

3,6-Bis(benzoylbiphenyl)ethynylcarbazole-9-carboxylic acid 1,1-dimethyltridecyl ester (e): Application of Sonogashira's general procedure for alkyne coupling ${ }^{5,6}$ [d $(2.98 \mathrm{~g}, 6.34 \mathrm{mmol}), 4-$ benzoyl-4'-bromobiphenyl ( $4.49 \mathrm{~g}, 13.3 \mathrm{mmol}), \mathrm{Pd}_{2}(\mathrm{dba})_{3}(0.351 \mathrm{~g}, 0.380 \mathrm{mmol}), \mathrm{CuI}(0.0241 \mathrm{~g}$, $0.127 \mathrm{mmol}), \mathrm{PPh}_{3}(0.669 \mathrm{~g}, 2.54 \mathrm{mmol})$ in $\mathrm{Et}_{3} \mathrm{~N}(17.0 \mathrm{~mL})$ and $\left.\mathrm{DMF}(32 \mathrm{~mL})\right]$ gave the product as a yellow solid $(4.29 \mathrm{~g}, 69 \%) .{ }^{1} \mathrm{H} \mathrm{NMR}\left(\mathrm{CDCl}_{3}, 400 \mathrm{MHz}\right): \delta 8.29(\mathrm{~d}, J=8.6 \mathrm{~Hz}, 2 \mathrm{H}), 8.21(\mathrm{~d}$, $J=1.8 \mathrm{~Hz}, 2 \mathrm{H}), 7.92(\mathrm{~d}, J=8.8 \mathrm{~Hz}, 4 \mathrm{H}), 7.85(\mathrm{~m}, 4 \mathrm{H}), 7.74(\mathrm{~d}, J=8.7 \mathrm{~Hz}, 4 \mathrm{H}), 7.67-7.71(\mathrm{~m}$, $10 \mathrm{H}), 7.61(\mathrm{~m}, 2 \mathrm{H}), 7.52(\mathrm{~m}, 4 \mathrm{H}), 2.07\left[\mathrm{~m}, 2 \mathrm{H}, \mathrm{OC}\left(\mathrm{CH}_{3}\right)_{2} \mathrm{CH}_{2}\left(\mathrm{CH}_{2}\right)_{10} \mathrm{CH}_{3}\right], 1.75[\mathrm{~s}, 6 \mathrm{H}$, $\left.\mathrm{OC}\left(\mathrm{CH}_{3}\right)_{2} \mathrm{CH}_{2}\left(\mathrm{CH}_{2}\right)_{10} \mathrm{CH}_{3}\right], 1.23-1.51\left(\mathrm{~m}, 20 \mathrm{H}, \mathrm{OC}\left(\mathrm{CH}_{3}\right)_{2} \mathrm{CH}_{2}\left(\mathrm{CH}_{2}\right)_{10} \mathrm{CH}_{3}\right], 0.87$ (t, $J=6.6 \mathrm{~Hz}$, $\left.3 \mathrm{H}, \mathrm{OC}\left(\mathrm{CH}_{3}\right)_{2} \mathrm{CH}_{2}\left(\mathrm{CH}_{2}\right)_{10} \mathrm{CH}_{3}\right] ;{ }^{13} \mathrm{C}$ NMR $\left(\mathrm{CDCl}_{3}, 100 \mathrm{MHz}\right): \delta 196.3$ (ArCOAr), 150.5 (NCOO), 144.3, 139.5, 138.5, 137.6, 136.5, 132.4, 132.2, 131.0, 130.8, 130.0, 128.3, 127.2, $\begin{array}{lllllll}126.8, & 125.2, & 123.3, & 123.1, & 117.9, & 116.4, & 90.9\end{array}$ [ArCCAr], 88.6 [ArCCAr], 87.4 [OC $\left.\left(\mathrm{CH}_{3}\right)_{2} \mathrm{CH}_{2}\left(\mathrm{CH}_{2}\right)_{5} \mathrm{CH}_{3}\right], 40.6,31.9,29.9,29.6$ (br, signal overlap), 29.5, 29.4, 29.3, 26.4, 24.1, 22.7, 14.1; MS (FAB): m/z (\%): 982.5 (2), 772.2 (5), 460.1 (3), 307.1 (29), 154.1 (100); HR-MS $\left(\mathrm{C}_{70} \mathrm{H}_{63} \mathrm{NO}_{4}\right)$ : calcd 982.4835, found 982.4839; TLC R $=0.18\left(\mathrm{CH}_{2} \mathrm{Cl}_{2} / n\right.$-Hexane 4/1); Anal. Calcd for $\mathrm{C}_{65} \mathrm{H}_{53} \mathrm{NO}_{4}$ (912.4): C, 85.59; H, 6.46; N, 1.43; Found: C, 85.67; H, 6.39; N, 1.66 .

ACTC: ${ }^{7}$ In an argon filled glove box, a solution of molybdenum triamide ${ }^{8,9}(67.9 \mathrm{mg}, 0.102$ mmol) and $p$-nitrophenol $(42.5 \mathrm{mg}, 0.305 \mathrm{mmol})$ in 1,2,4-trichlorobenzene $(14 \mathrm{~mL}$, anhydrous grade) was added to a solution of monomer $\mathbf{e}(1.00 \mathrm{~g}, 1.02 \mathrm{mmol})$ in 1,2,4-trichlorobenzene (28 $\mathrm{mL}$ ). The flask was sealed and removed from the glove box. The resulting mixture was stirred for $22 \mathrm{~h}$ at $30^{\circ} \mathrm{C}$. After removal of the precipitate by vacuum filtration, the solvent was removed by distillation under high vacuum $\left(50^{\circ} \mathrm{C}, 1 \mathrm{mmHg}\right) . \mathrm{CH}_{2} \mathrm{Cl}_{2}(15 \mathrm{~mL})$ was added to the residue and the resulting mixture was stirred vigorously until the product became fine particles. After filtration, the product was washed with $\mathrm{CH}_{2} \mathrm{Cl}_{2}(3 \times 5 \mathrm{~mL})$ to give ACTC macrocycle as a white solid (0.366 g, 81\%). ${ }^{1} \mathrm{H}$ NMR $\left(\mathrm{CDCl}_{3}, 500 \mathrm{MHz}\right): \delta 8.10(\mathrm{~d}, J=8.6 \mathrm{~Hz}, 8 \mathrm{H}), 8.00(\mathrm{~s}, 8 \mathrm{H}), 7.44$ 
$(\mathrm{d}, \quad J=8.6 \mathrm{~Hz}, \quad 8 \mathrm{H}), \quad 2.11 \quad\left[\mathrm{~m}, \quad 8 \mathrm{H}, \quad \mathrm{OC}\left(\mathrm{CH}_{3}\right)_{2} \mathrm{CH}_{2}\left(\mathrm{CH}_{2}\right)_{10} \mathrm{CH}_{3}\right], \quad 1.80 \quad[\mathrm{~s}, \quad 24 \mathrm{H}$, $\left.\mathrm{OC}\left(\mathrm{CH}_{3}\right)_{2} \mathrm{CH}_{2}\left(\mathrm{CH}_{2}\right)_{10} \mathrm{CH}_{3}\right], 1.23-1.54$ (m, $\left.80 \mathrm{H}, \mathrm{OC}\left(\mathrm{CH}_{3}\right)_{2} \mathrm{CH}_{2}\left(\mathrm{CH}_{2}\right)_{10} \mathrm{CH}_{3}\right], 0.87$ (t, $J=6.6 \mathrm{~Hz}$, $\left.12 \mathrm{H}, \mathrm{OC}\left(\mathrm{CH}_{3}\right)_{2} \mathrm{CH}_{2}\left(\mathrm{CH}_{2}\right)_{10} \mathrm{CH}_{3}\right] ;{ }^{13} \mathrm{C}$ NMR $\left(\mathrm{CDCl}_{3}, 125 \mathrm{MHz}\right): \delta 150.5$ (NCOO), 138.0, 130.7, 125.1, 122.4, 118.2, 116.0, 89.1 [ArCCAr], 87.0 [OC( $\left(\mathrm{CH}_{3}\right)_{2} \mathrm{CH}_{2}\left(\mathrm{CH}_{2}\right)_{5} \mathrm{CH}_{3}$ ], 40.8, 31.9, 30.0, 29.7 (br, signal overlap), 29.6, 29.5, 29.4, 26.4, 24.2, 22.7, 14.1; MS (FD): m/z (\%): 1773.3 (21), 887.0 (100), 525.3 (66); Anal. Calcd for $\mathrm{C}_{120} \mathrm{H}_{148} \mathrm{~N}_{4} \mathrm{O}_{8}$ (1773.1): C, 81.22; H, 8.41; N, 3.16; Found: C, 80.93; H, 8.05; N, 3.24; GPC $2030\left(M_{\mathrm{n}}\right), 1.02\left(M_{\mathrm{w}} / M_{\mathrm{n}}\right)$.
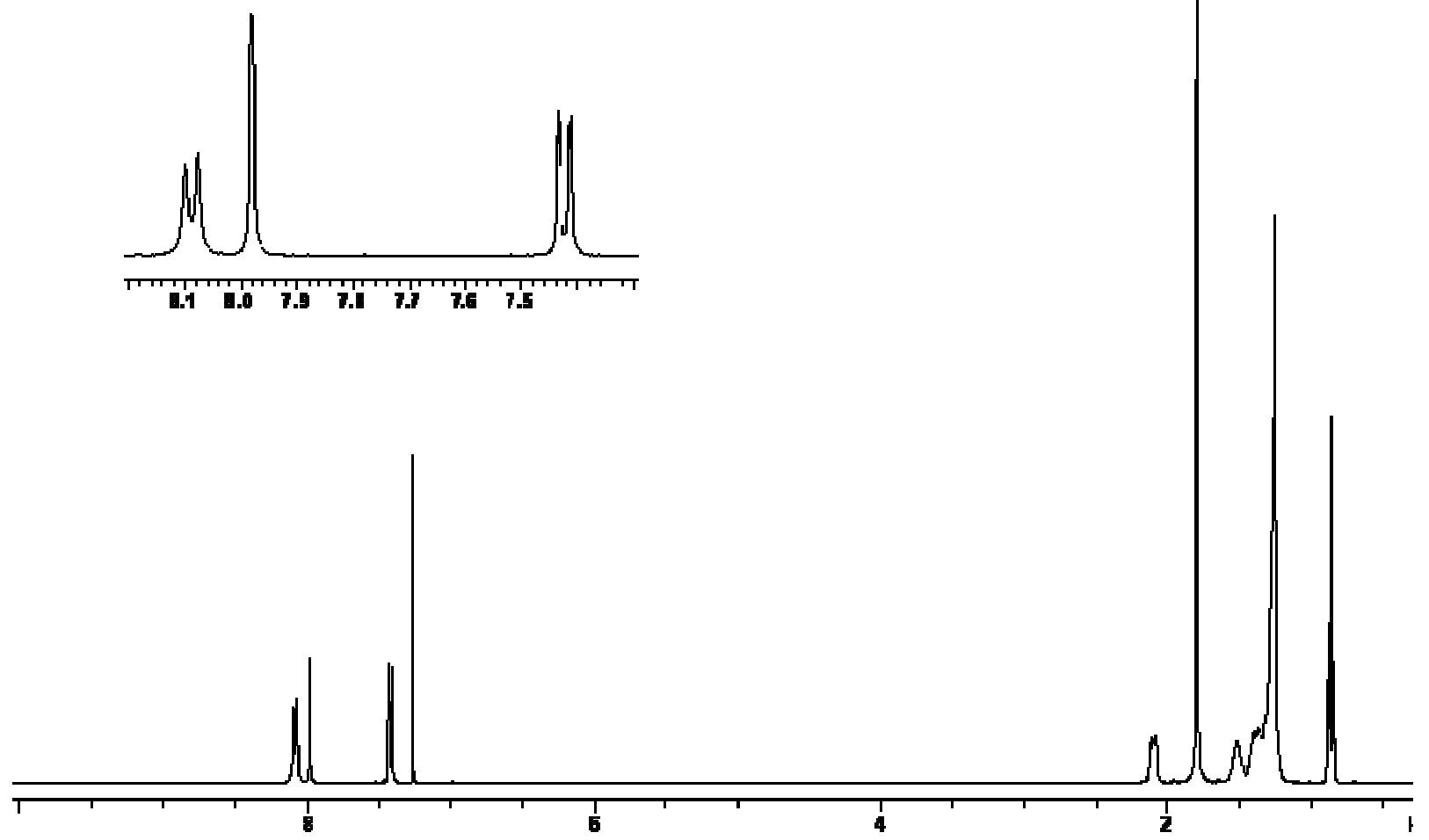

Figure S1. ${ }^{1} \mathrm{H}$ NMR spectrum of ACTC $\left(\mathrm{CDCl}_{3}, 500 \mathrm{MHz}, 40{ }^{\circ} \mathrm{C}\right)$. 


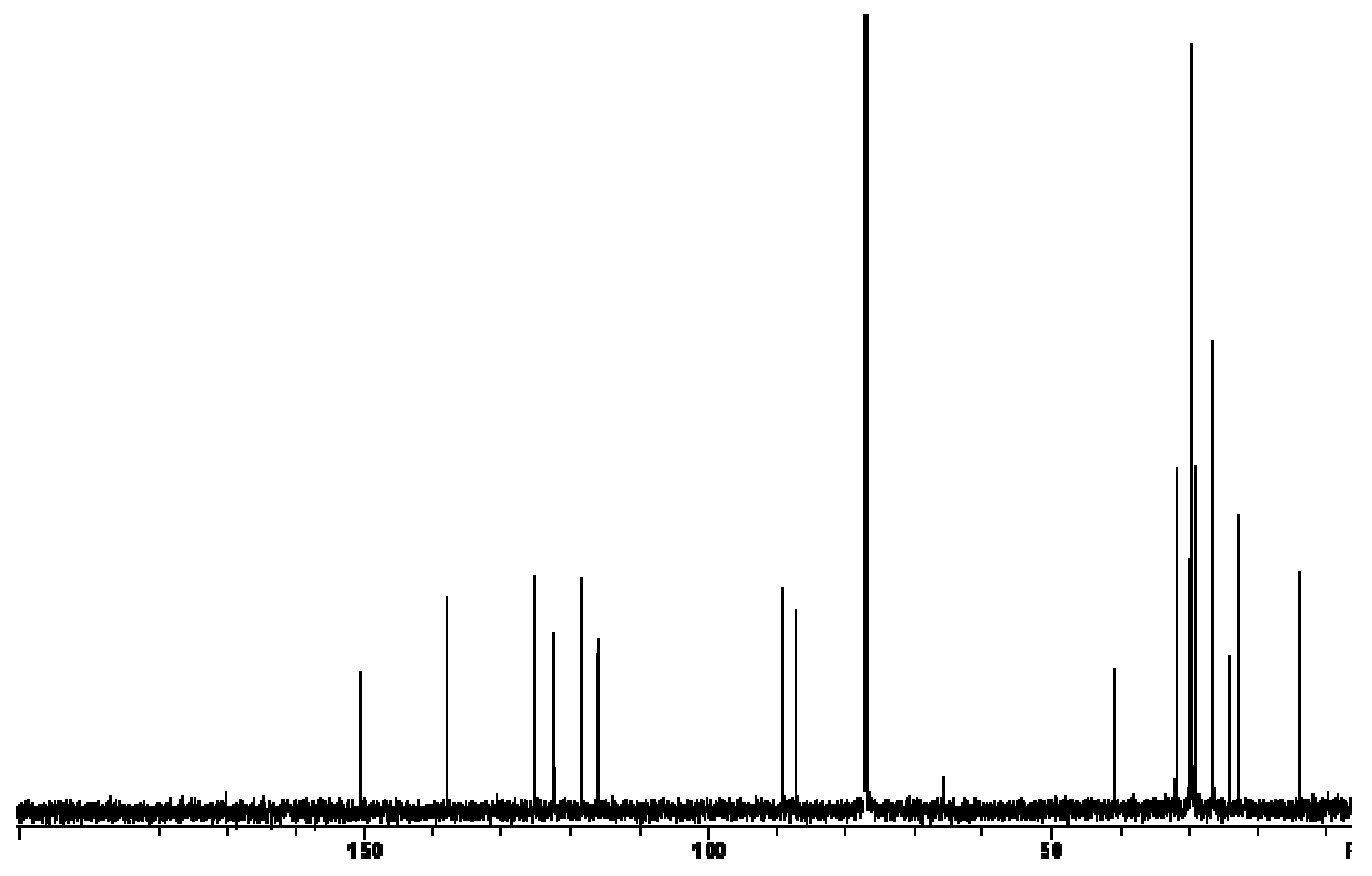

Figure S2. ${ }^{13} \mathrm{C}$ NMR spectrum of $\mathrm{ACTC}\left(\mathrm{CDCl}_{3}, 125 \mathrm{MHz}, 40{ }^{\circ} \mathrm{C}\right)$.

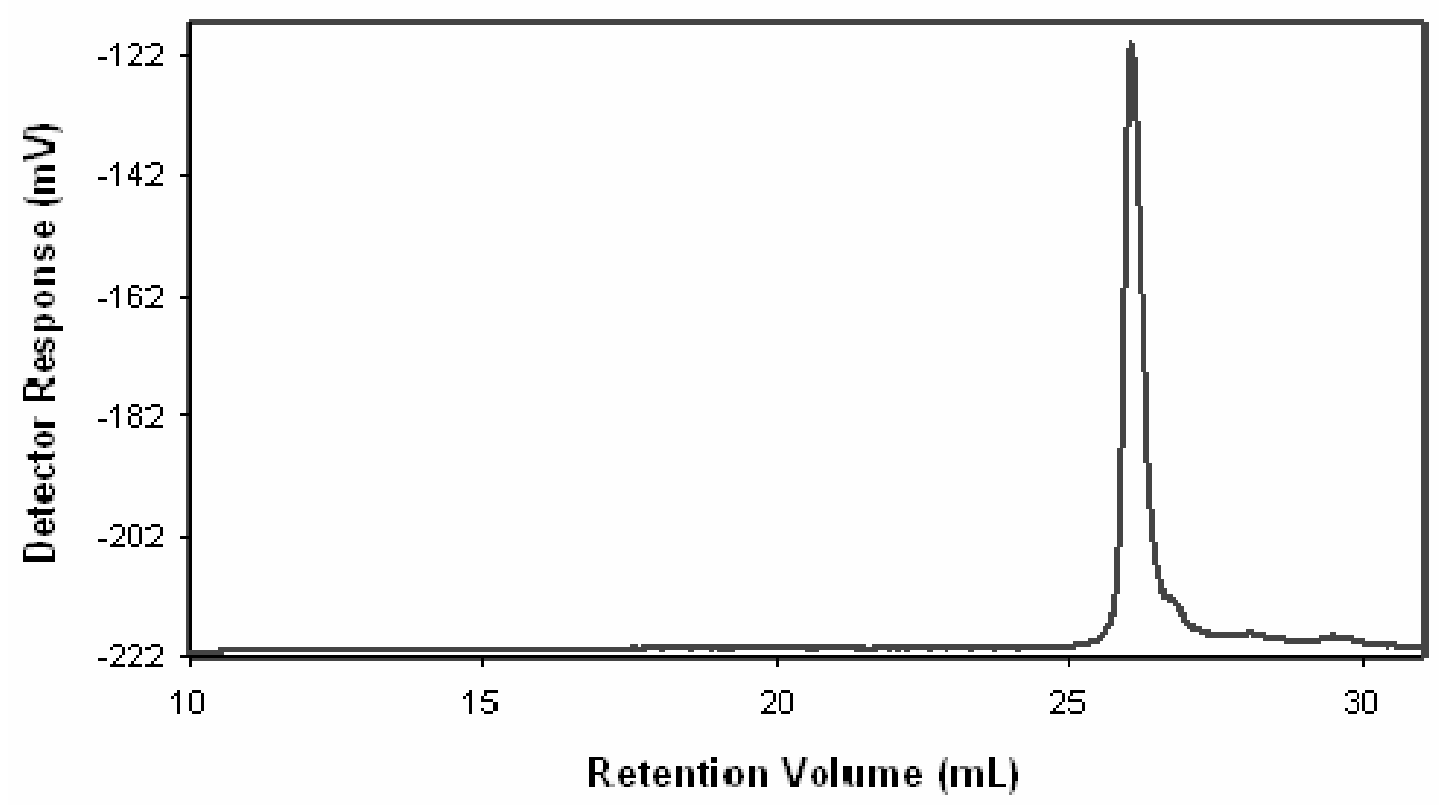

Figure S3. GPC trace of ACTC (THF, $\left.25^{\circ} \mathrm{C}\right)$. 


\section{Fabrication and microscopy characterization of ACTC films}

A uniform film of ACTC was fabricated by spin-casting one drop of the ACTC solution in THF onto a glass cover slip at a speed of 1,500 rpm. By changing the concentration of the ACTC solution $(0.2-1.0 \mathrm{mM})$, different thickness of films were obtained as characterized below with AFM and spectroscopy methods. The rigid, planar geometry of the ACTC molecule (including both core and the side chains) affords effective cofacial stacking between molecules, leading to formation of one-dimensional, fibril nanostructures (inset of Figure 2 and Figure S4). Indeed, the long nanofibril structures shown in Figure S4 were fabricated simply by depositing a small amount of THF solution of ACTC (2 mM) onto a carbon grid. The long-range molecular stacking is conducive to the $\pi-\pi$ electronic interaction along the long-axis, thus resulting in efficient exciton migration along the fiber. Moreover, entangled piling of large number of the nanofibrils produces extensively porous structure and large surface area of the film, which are both conducive for increasing the adsorption of explosives molecules.

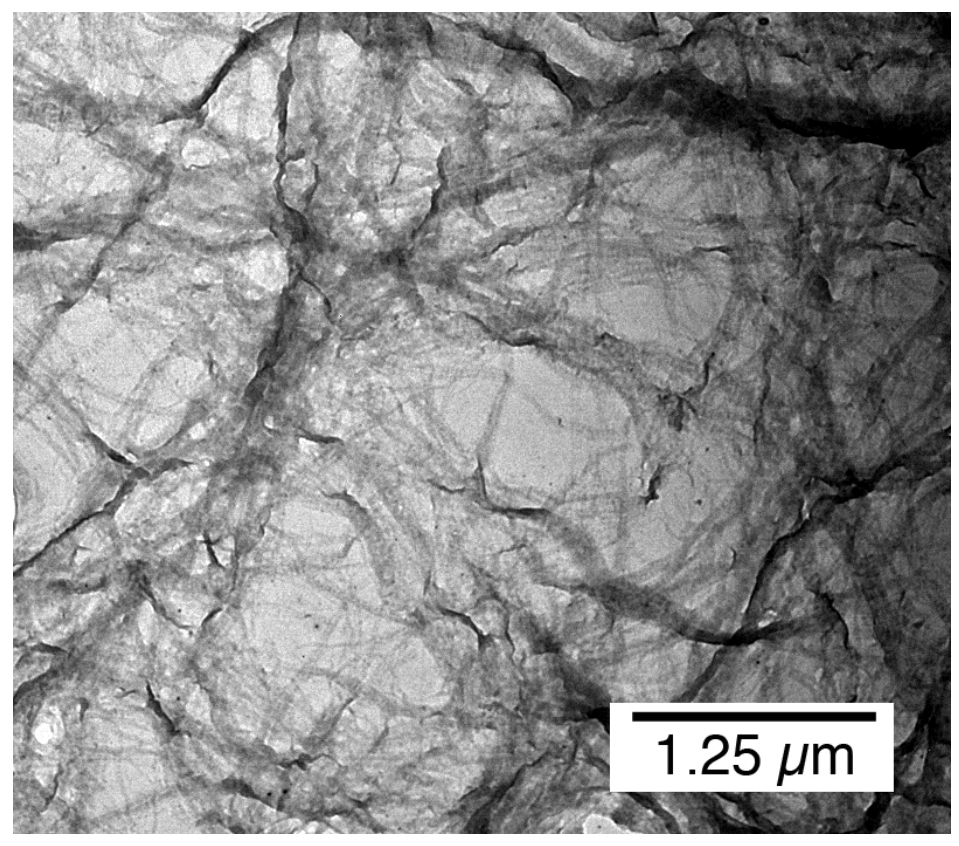

Figure S4. (right) TEM image of ACTC nanofibrils formed by casting a small amount of THF solution $(2 \mathrm{mM})$ onto a holey carbon grid, for which a filter paper was used as the substrate to drain the excessive solution.

\section{Optical spectroscopic characterization of molecules and films}

Figure S5 shows the absorption and fluorescence spectra of ACTC in both solutions and solid state. ACTC dissolved in a solution is highly fluorescent, with quantum yield of 0.7 (calibrated with pyrene dissolved in cyclohexane, with yield of $0.32^{10}$ ). Upon aggregate (molecular stacking), the strong $\pi-\pi$ interaction (i.e. electronic coupling) between molecules shifts the emission band to longer wavelength by about $70 \mathrm{~nm}$. Consistent with the emission spectral change, the absorption transition around $340 \mathrm{~nm}$ is relatively enhanced upon molecular stacking. These spectral changes are characteristic of $\pi$-stacked molecular aggregate, ${ }^{11-17}$ for 
which like an excimer, the collective electronic features are significantly different from the individual component molecules. The fluorescence quantum yield of the ACTC film (ca. 0.19) was also estimated by calibration with pyrene solution in cyclohexane, with yield of $0.32 .{ }^{10}$

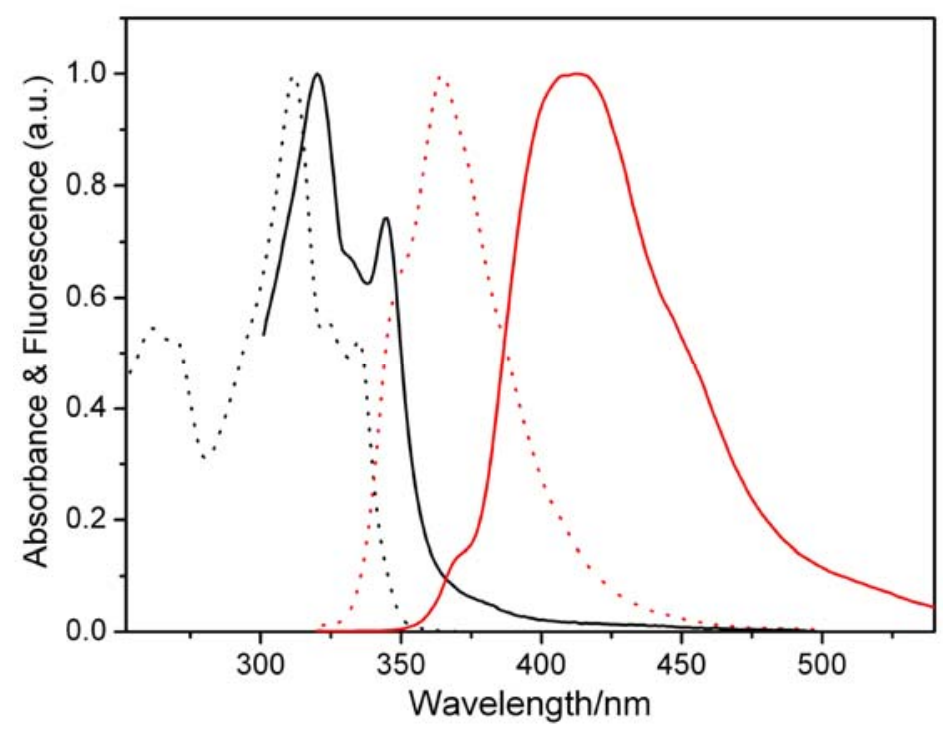

Figure S5. Absorption (black) and fluorescence (red) spectra of molecularly dissolved solution (dotted) and drop-cast film (solid) of ACTC. The solution used for spectral measurement was 1 $\mu \mathrm{M}$ of ACTC dissolved in THF. The film was cast from a $2 \mathrm{mM}$ THF solution of ACTC. All spectra normalized to the maxima.

Figure S6 shows the absorption spectra of DNT and TNT molecules. Apparently, both molecules absorb irradiation below $300 \mathrm{~nm}$. In comparison, the emission of ACTC film is far above $350 \mathrm{~nm}$ as shown in Figure S5. The lack of overlap between the ACTC emission and the absorption of DNT and TNT excludes the probability of energy transfer from the excited ACTC to the explosives quencher. Thereby, the effective fluorescence quenching observed in this study is solely due to the photoinduced electron transfer from the singlet state of ACTC to the ground state of the quencher. Such a charge transfer process is consistent with the strong oxidation potential of DNT and TNT, as previously evidenced in the fluorescence quenching of conjugate polymers. ${ }^{2,18-20}$

Our ab initio calculation shows that the driving force of the photoinduced electron transfer between ACTC molecule and the quencher is as large as 2.4 and $1.9 \mathrm{eV}$ for TNT and DNT, respectively (Figure S7). Such large driving force ensures efficient electron transfer, and thus fluorescence quenching. The larger driving force for TNT implies a stronger quenching efficiency compared to DNT, as indeed observed in this study, i.e. comparable quenching was obtained for TNT $(83 \%)$ and DNT (90) at adsorption equilibrium, whereas the vapor pressures of the two quenchers are different by as large as 20 times, $100 \mathrm{ppb}$ for DNT and only $5 \mathrm{ppb}$ for TNT. Upon molecular stacking in solid state, the LUMO level of ACTC decreases only about $0.1 \mathrm{eV}$ based on the shift of absorption band shown in Figure S5. Such slight decrease does not affect significantly the electron transfer process indicated in Figure S7. 


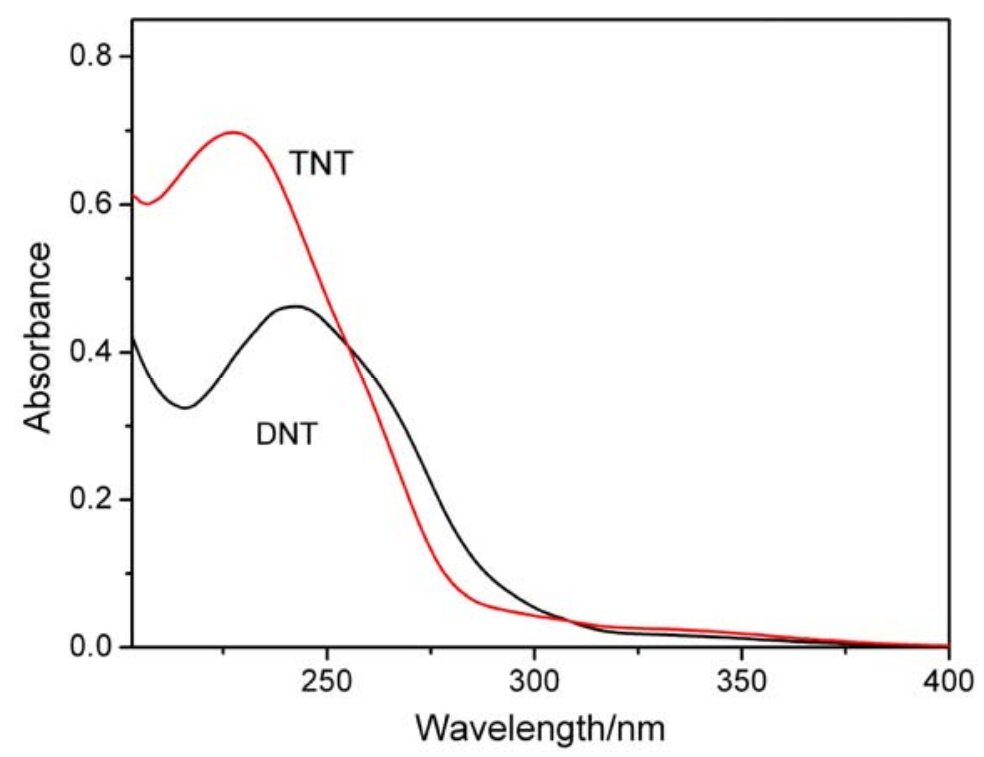

Figure S6. Absorption spectra of DNT (black) and TNT (red) dissolved in methanol at a concentration of $50 \mu \mathrm{M}$.

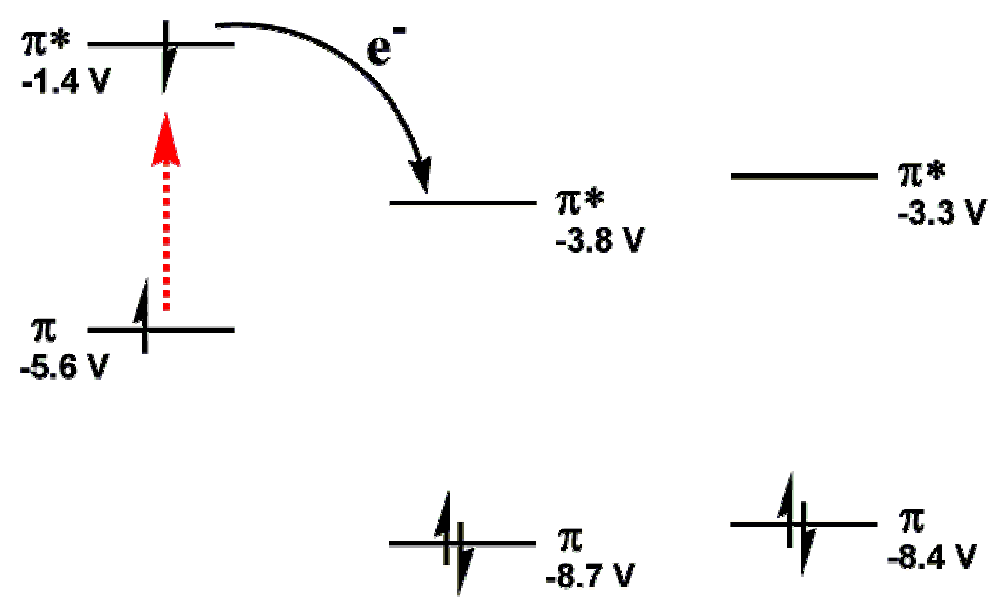

\section{$\begin{array}{lll}\text { ACTC } & \text { TNT }\end{array}$}

Figure S7. Energy levels of HOMO $(\pi)$ and LUMO $\left(\pi^{*}\right)$ orbitals of ACTC, TNT and DNT showing the large driving force of electron transfer from the photoexcited state of ACTC to TNT $(2.4 \mathrm{eV})$ and DNT $(1.9 \mathrm{eV})$. Geometry optimization and energy calculation were performed with density-functional theory (B3LYP/6-31g*) using Gaussian 03 package.

\section{Calibration of film thickness via AFM and optical spectrometry}

Films of various thicknesses were fabricated by spin-casting different concentrations of the ACTC solution in THF, ranging from $0.2 \mathrm{mM}$ to $1.0 \mathrm{mM}$. As expected, the absorbance of the film is linearly proportional to the concentration of the casting solution (Figure S8). Since the absorbance is proportional to the film thickness (Beer's law), the calibration data shown in 
Figure S8 demonstrates linear dependence of film thickness on the concentration of casting solution. Due to the low absorbance (and thus minimal self-absorption of the fluorescence) of the film within this thickness range, the same linear dependence was also observed for the fluorescence intensity measured for the film, as shown in Figure S9. The calibration ratios (the slope of the linear fitting shown in Figure S8 and S9 after normalization) obtained for the UV-vis absorption and fluorescence measurements are remarkably consistent, with values of $1.0 \pm 0.08$ and $1.02 \pm 0.04$, respectively. With such spectrometry calibration, we could estimate the thickness of all the films based on AFM measurement of one of the films. Here, we measured the thickness of the thinnest film with tapping mode AFM, and obtained an average thickness of $18 \mathrm{~nm}$. Based on this value, the thicknesses of other four films (shown in Figure S8 and S9) were deduced from the linear calibration curve: $36,54,72,90 \mathrm{~nm}$.

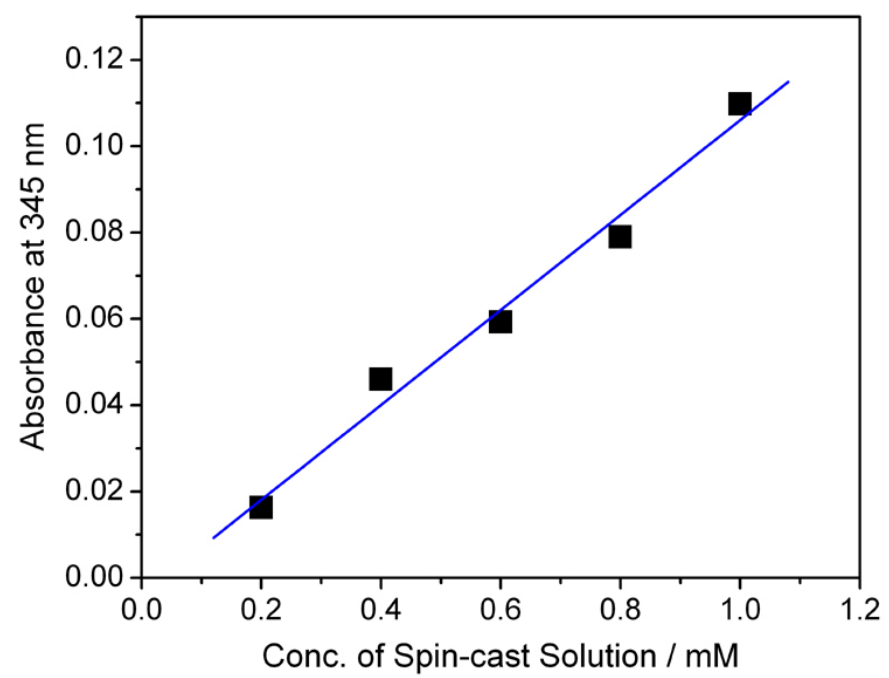

Figure S8. Dependence of absorption of ACTC film at $345 \mathrm{~nm}$ (the maximum at long wavelength) on the concentration of the casting solution.

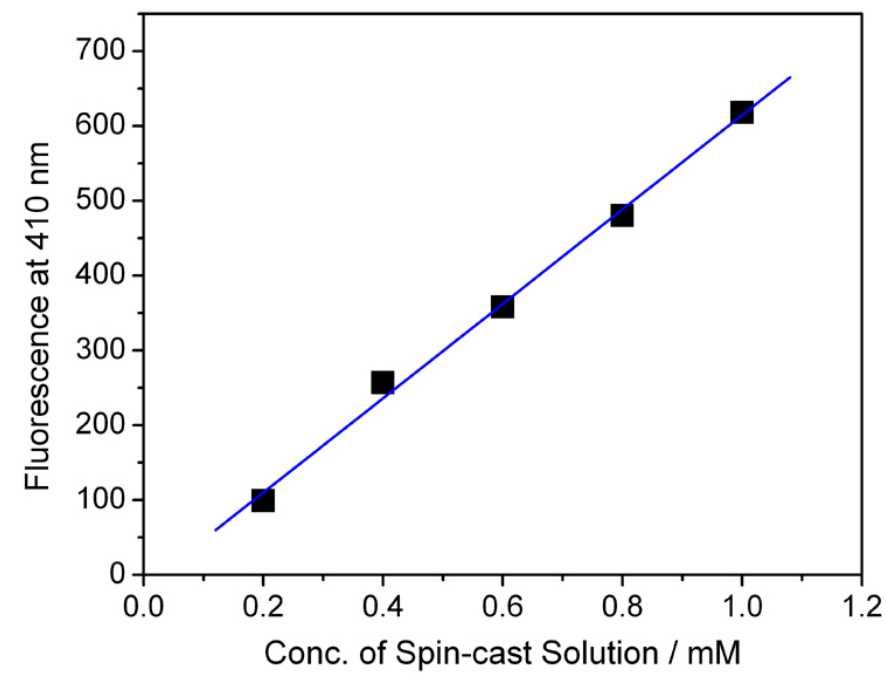

Figure S9. Dependence of fluorescence intensity of ACTC film at $410 \mathrm{~nm}$ (the maximum) on the concentration of the casting solution. 


\section{Fluorescence spectra of ACTC film upon exposure to DNT vapor}

As performed for TNT (Figure 1), the DNT quenching was also monitored by measuring the fluorescence spectra of an ACTC film $(90 \mathrm{~nm})$ at different time intervals after exposure to the saturated vapor of DNT (Figure S10). Within just $10 \mathrm{~s}$ after exposure, the fluorescence was quenched about $90 \%$. Further exposure did not increase the quenching significantly, implying a fast response to DNT to reach the adsorption equilibrium. The faster response of DNT (compared to TNT) is likely due to the higher vapor pressure (100 ppb).

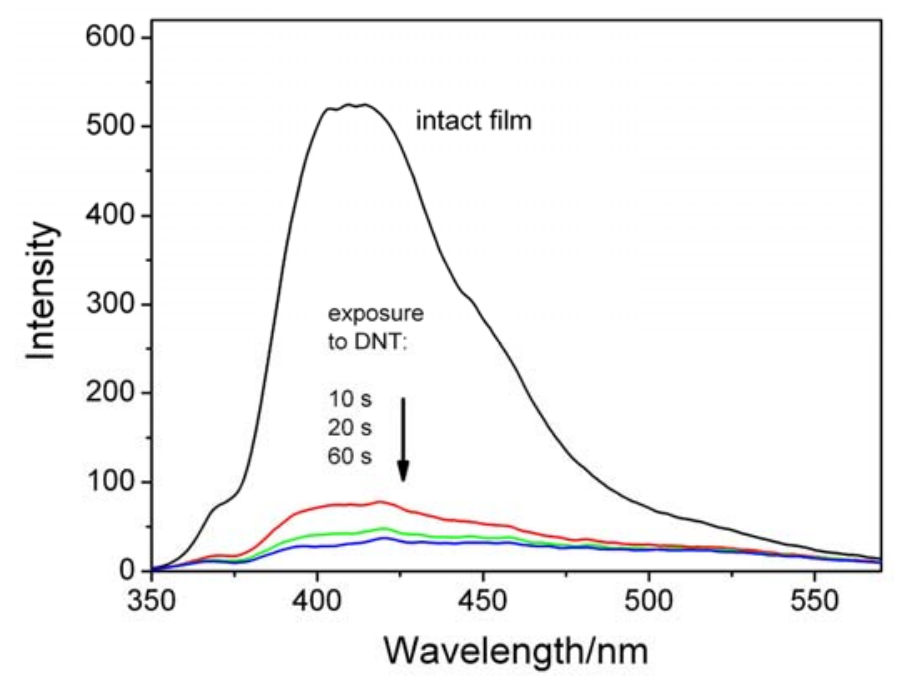

Figure S10. Fluorescence spectra of a $90 \mathrm{~nm}$ ACTC film upon exposure to saturated vapor of DNT (100 ppb) at different times.

\section{Time course of TNT quenching vs. thickness of films}

Figure S11 shows the full time-course of TNT quenching for 5 ACTC films with different thicknesses. Within the experimental error, no thickness-dependence was found for the whole time range of exposure. The response rate is approximately the same for all the five films studied. As mentioned in the Communication context, the slightly lower quenching found for the thinnest film was probably due to the evaporation of quencher molecules from the film during the course of transferring the sample from the explosives jar to the fluorometer. In general, a thin film (in porous structure) cannot hold the gaseous adsorbates as effectively as the thick films. We assume that with an in situ fluorescence monitoring the quenching efficiency of the thin film should be in the same range as the thick films. 


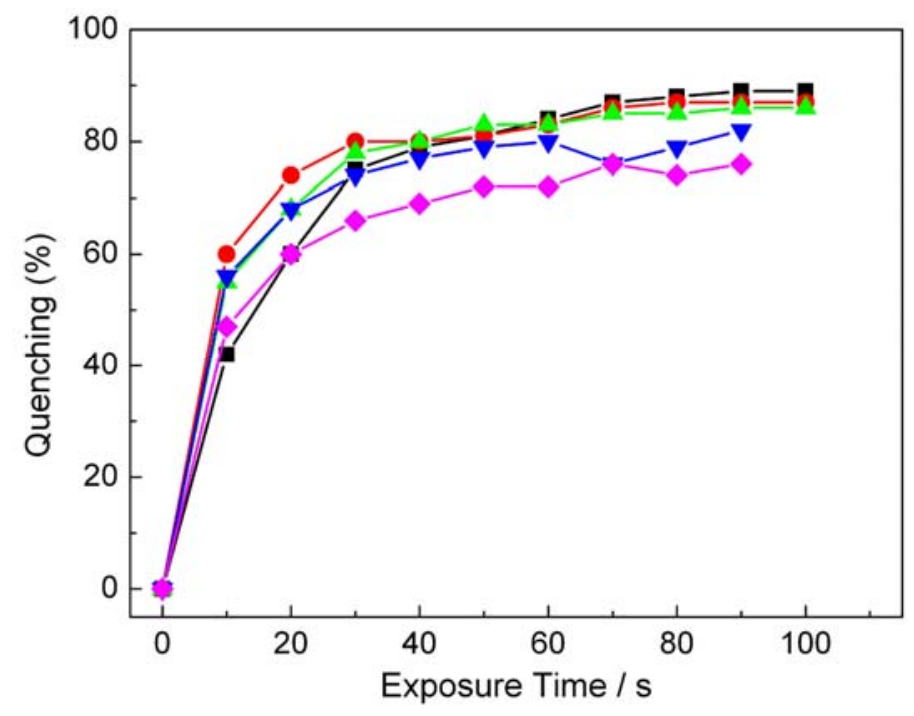

Figure S11. Fluorescence quenching (\%) of the ACTC film as a function of exposure time to TNT vapor. Five different thicknesses of films were employed: $90 \mathrm{~nm}(\bullet), 72 \mathrm{~nm}(\bullet), 54 \mathrm{~nm}$ $(\mathbf{\Delta}), 36 \mathrm{~nm}(\mathbf{\nabla}), 18 \mathrm{~nm}(\bullet)$.

\section{Recovery of film fluorescence by exposure to hydrazine}

The fluorescence of ACTC film after exposure to explosives can be recovered simply by exposing the film to ambient air under dark. However such a recovery takes long time, usually a few days, to reach the fluorescence intensity of the pristine film. In this study we found an effective way to speed up the recovery process by immersing the used film in a saturated vapor of hydrazine (ca. $140 \mathrm{ppm}$ ). As shown in Figure S12, within only one hour the fluorescence was recovered about $90 \%$. Upon immersing for longer time, $100 \%$ recovery could be obtained. Such a speedy recovery is favorable for developing the sensing materials in practical applications.

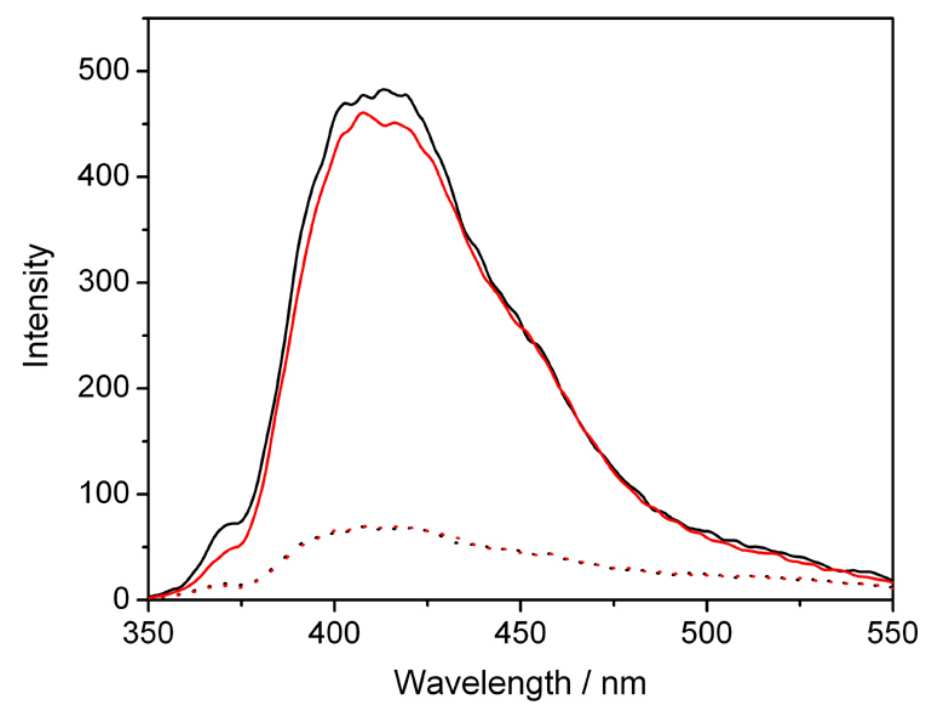


Figure S12. Fluorescence spectra of a $90 \mathrm{~nm}$ ACTC film: pristine film (black-solid), after exposure to DNT vapor (5 ppb) for $60 \mathrm{~s}$ (black-dotted), after recovery in a hydrazine vapor (140 $\mathrm{ppm}$ ) for $1 \mathrm{~h}$ (red-solid), and after second time exposure to the DNT vapor (red-dotted).

\section{Effects of molecular configuration: TDTC vs. ACTC}

The co-facial stacking of planar molecules is largely dependent on the molecular configuration, including both the backbone scaffold and the side-chain attachments. ${ }^{11,12,14}$ Compared to the tetracycle (TDTC, shown in Figure S13) previously reported from our lab, ${ }^{13}$ where the four alkyl side chains are directly linked to the central core, the ACTC tetracycle reported in this paper is modified with four different side-chains, which are attached to the central scaffold through a carbonyl link. Different side-chain attachments produce different geometries of the molecular surface as evidenced by the DFT calculation (Figure S13). While the direct attachment of alkyl chains produces a molecule in saddle-like conformation, the incorporation of carbonyl group at the link site tunes the side chain co-planar with the central scaffold, forming a geometry that is the most favorable for co-facial molecular stacking. Indeed, for ACTC nanofibril structure can be easily fabricated using various solution and surface processing (e.g., direct dispersion or phase transfer between a good and poor solvent, gelation in cyclohexane, or evaporation of a freshly cast film on glass), whereas the nanofibril fabrication of TDTC can only be performed via gelation in an appropriately selected solvent, such as cyclohexane.

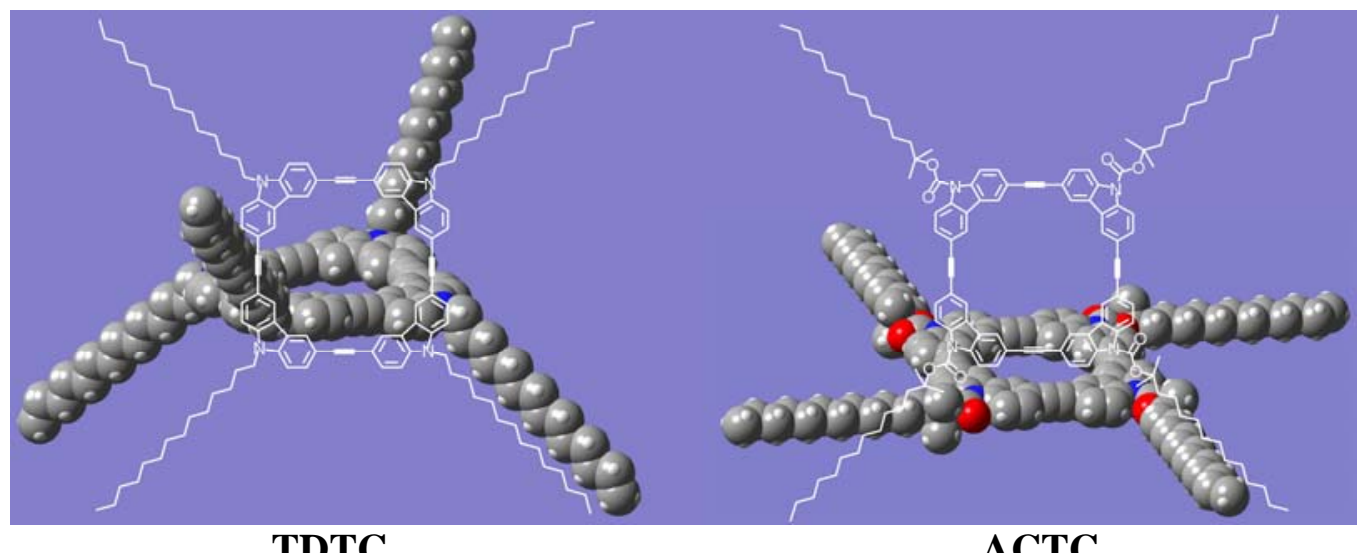

TDTC

ACTC

Figure S13. Side-chain effect on configuration: a carbonyl joint forces co-planar configuration (Gaussian optimization at B3LYP/6-31G*).

In general, the side-chain design rule for organized one-dimensional molecular stacking lies in the minimization of steric hindrance, which thus favors the co-facial $\pi-\pi$ interaction between two adjacent molecules. To this end, side chains in linear configuration (e.g., alkyl chains) and linked to the backbone scaffold in co-planar geometry are usually desirable for fabricating highly organized nanofibrils dominated by co-facial molecular stacking. Side chains in branched configuration usually produce significant steric hindrance for molecular stacking, ${ }^{14}$ thereby leading to weak $\pi-\pi$ interaction and electronic coupling, which in turn decreases the exciton migration among the molecules. 
As a comparison, the film cast from a TDTC solution in THF was also tested for the fluorescence quenching by the two explosives, DNT and TNT (Figure S14). Upon exposure to the saturated vapor of DNT and TNT, the fluorescence of TDTC film was quenched only 53\% and $50 \%$, respectively, at adsorption equilibrium after $80 \mathrm{~s}$ of exposure. These values are significantly lower than those obtained for the ACTC film under the same conditions, 90\% and $83 \%$ for DNT and TNT, respectively. The lower quenching efficiency observed for TDTC films is likely due to the weaker $\pi-\pi$ interaction between the molecules (as discussed above), which leads to less efficient exciton migration.
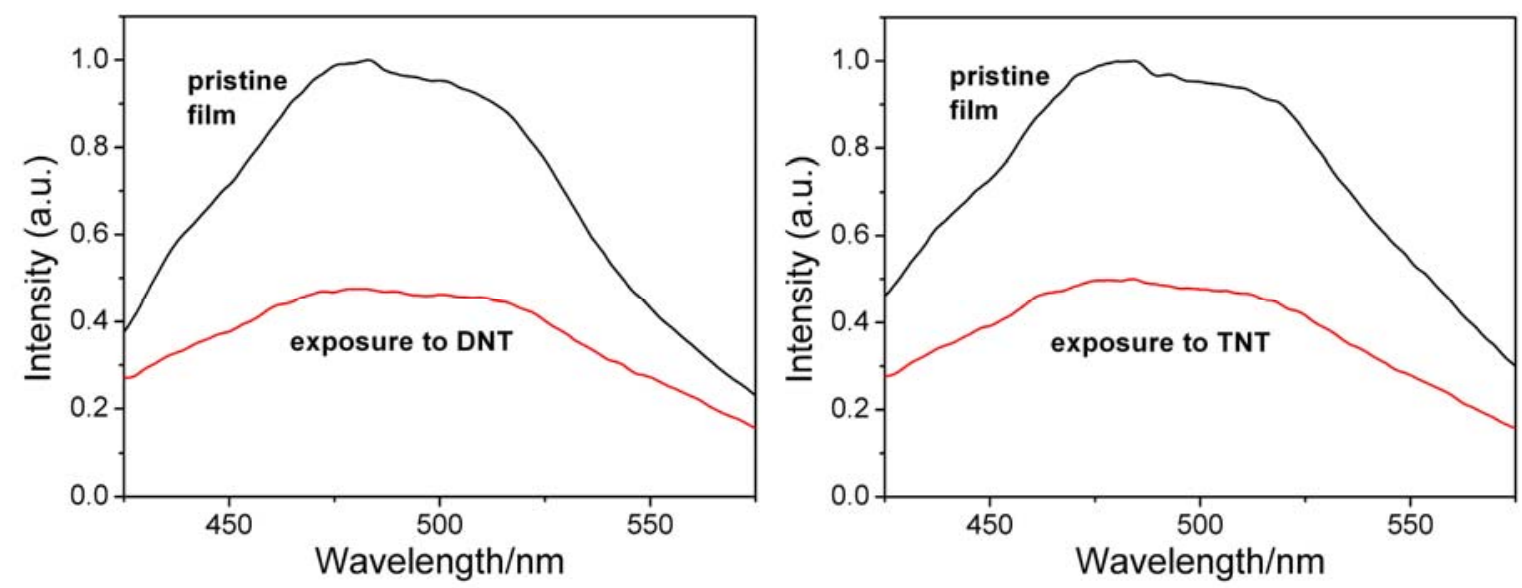

Figure S14. Fluorescence spectra of a TDTC film (spin-cast from a $1.0 \mathrm{mM}$ THF solution) upon exposure to saturated vapor of DNT (100 ppb) and TNT (5 ppb) for $80 \mathrm{~s}$.

$\pi *$

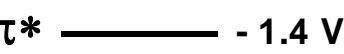

$\pi *$

$1.3 \mathrm{~V}$

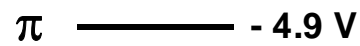

$\pi \longrightarrow-5.6 \mathrm{~V}$

ACTC

TDTC

Figure S15. Energy levels of HOMO $(\pi)$ and LUMO $\left(\pi^{*}\right)$ orbitals of ACTC and TDTC. Geometry optimization and energy calculation were performed with density-functional theory (B3LYP/6-31g*) using Gaussian 03 package.

Figure S15 shows the energy levels of HOMO $(\pi)$ and LUMO $\left(\pi^{*}\right)$ orbitals of ACTC and TDTC molecules. The similar level of LUMO implies that the two molecules afford approximately the same driving force for the electron transfer from the excited state to the explosive quenchers (as shown in Figure S7). This further supports that the observed difference 
in quenching efficiency for TDTC and ACTC films is primarily due to the different molecular stacking conformation, which in turn determines the efficiency of exciton migration.

\section{Estimation of TNT uptake and implication of amplified fluorescence quenching}

The amplified fluorescence quenching observed for the nanofibril is likely due to the intermolecular electronic coupling $(\pi-\pi$ interaction), as evidenced by many theoretical calculation and modeling. ${ }^{21-23}$ Such enhanced exciton migration is different in mechanism from the polymer-chain-mediated exciton migration, which relies on the conjugated, intramolecular interaction.

Here we performed some calculations to estimate the uptake of TNT by the nanofibril film within the sensing response time, $10 \mathrm{~s}$, at which about $50 \%$ of fluorescence is quenched. As seen below, the large molar ratio of the amount of ACTC molecules to the TNT uptake is consistent with the amplified fluorescence quenching that was proposed.

For a film, the uptake of TNT (M) within a certain amount of time can be calculated by, ${ }^{1}$

$\mathbf{M}=\mathbf{D} \cdot \mathbf{S} \cdot \mathbf{A} \cdot \mathbf{t} / \mathbf{L}$

where $\mathbf{D}$ is the diffusion coefficient $\left(\mathrm{cm}^{2} / \mathrm{s}\right)$ of TNT within the film, $\mathbf{S}$ is the solubility $\left(\mathrm{g} / \mathrm{cm}^{3}\right)$ of TNT within the film, A is the area $\left(\mathrm{cm}^{2}\right)$ of the film exposed to TNT, $\mathbf{L}$ the thickness $(\mathrm{cm})$ of the film, and $\mathbf{t}$ is the total exposure time (s) to TNT. Here, we take the average values for the parameters $\mathbf{D}\left(1.7 \times 10^{-9} \mathrm{~cm}^{2} / \mathrm{s}\right)$ and $\mathbf{S}\left(1.0 \times 10^{-6} \mathrm{~g} / \mathrm{cm}^{3}\right)$ that were obtained at the saturated vapor pressure of TNT for five different polymers, ${ }^{1}$ which are assumed to be similar or comparable to ACTC materials with regard to diffusivity and solubility. The ACTC film fabricated in our study (used in Figure 1) is about $6.5 \mathrm{~cm}^{2}$ large and $90 \mathrm{~nm}\left(9 \times 10^{-6} \mathrm{~cm}\right)$ thick. Then, the total TNT uptake within the sensing response time $(10 \mathrm{~s})$ can be calculated, ca. $1.2 \times 10^{-8} \mathrm{~g}$, or $\mathbf{5 . 3} \times \mathbf{1 0}^{-\mathbf{1 1}}$ mole (MW of TNT: 227).

The total amount of ACTC molecules within the film is ca. $1.6 \times 10^{-5} \mathrm{~g}$ or $\mathbf{9 . 0} \times \mathbf{1 0}^{-\mathbf{9}}$ mole (MW of ACTC: 1774.5). The molar ratio of TNT uptake to total ACTC molecules is about $\mathbf{1}$ : 170, clearly implying an amplified quenching of fluorescence mediated by the assembly (here the nanofibril) of the ACTC molecules, rather than the individual molecular chromophores.

Considering the nanofibril size, $10 \mathrm{~nm}$ in diameter and 1 micron in length, which correspond to about 45,000 ACTC molecules within one nanofibril, the number of TNT uptake per nanofibril is estimated as ca. 265, which corresponds to ca. $4 \mathbf{n m}$ separation between two adjacent TNT molecules adsorbed on the surface if assuming a uniform adsorption lined-up along the long axis of the nanofibril. This distance falls into the typical exciton migration range, $0-10 \mathrm{~nm}$, obtained for the organized organic semiconductors. ${ }^{2}$ However, in the real case of sensing, the adsorption of TNT molecules is not necessarily lined up along the nanofibril, and thus the longitudinal distance between two adsorbed molecules could be significantly larger than $4 \mathrm{~nm}$. The large distance (corresponding to the exciton migration length) thus obtained is consistent with the organized co-facial molecular stacking, which facilitates the one-dimensional exciton migration. ${ }^{21-23}$ 


\section{References:}

(1) Datar, A.; Oitker, R.; Zang, L. Chem. Commun. 2006, 1649-1651.

(2) Yang, J.-S.; Swager, T. M. J. Am. Chem. Soc. 1998, 120, 11864-11873.

(3) Pope, B. M.; Sheu, S.-J.; Stanley, R. L.; Tarbell, D. S.; Yamamoto, Y. Journal of Organic Chemistry 1978, 43, 2410-2414.

(4) Bailey, W. F.; Punzalan, E. R. Journal of Organic Chemistry 1990, 55, 5404-5406.

(5) Sonogashira, K.; Tohda, Y.; Hagihara, N. Tetrahedron Letters 1975, 4467-4470.

(6) Sonogashira, K.; Yatake, T.; Tohda, Y.; Takahashi, S.; Hagihara, N. Journal of the Chemical Society, Chemical Communications 1977, 291-292.

(7) Zhang, W.; Moore, J. S. J .Am. Chem. Soc 2004, 126, 12796.

(8) Zhang, W.; Kraft, S.; Moore, J. S. Chemical Communications (Cambridge, United Kingdom) 2003, 832-833.

(9) Zhang, W.; Kraft, S.; Moore, J. S. Journal of the American Chemical Society 2004, 126, 329-335.

(10) Berlman, I. B. Handbook of Fluorescence Spectra of Aromatic Molecules; Academic Press 1971.

(11) Hoeben, F. J. M.; Jonkheijm, P.; Meijer, E. W.; Schenning, A. P. H. J. Chem. Rev. 2005, 105, 1491-1546.

(12) Balakrishnan, K.; Datar, A.; Oitker, R.; Chen, H.; Zuo, J.; Zang, L. J. Am. Chem. Soc. 2005, 127, 10496-10497.

(13) Balakrishnan, K.; Datar, A.; Zhang, W.; Yang, X.; Naddo, T.; Huang, J.; Zuo, J.; Yen, M.; Moore, J. S.; Zang, L. J. Am. Chem. Soc. 2006, 128, 6576-6577.

(14) Balakrishnan, K.; Datar, A.; Naddo, T.; Huang, J.; Oitker, R.; Yen, M.; Zhao, J.; Zang, L. J. Am. Chem. Soc. 2006, 128, 7390-7398.

(15) Ahrens, M. J.; Sinks, L. E.; Rybtchinski, B.; Liu, W.; Jones, B. A.; Giaimo, J. M.; Gusev, A. V.; Goshe, A. J.; Tiede, D. M.; Wasielewski, M. R. J. Am. Chem. Soc. 2004, 126, 8284-8294.

(16) Wurthner, F. Chem. Commun. 2004, 1564-1579.

(17) Rybtchinski, B.; Sinks, L. E.; Wasielewski, M. R. J. Am. Chem. Soc. 2004, 126, 1226812269.

(18) Yang, J.-S.; Swager, T. M. J. Am. Chem. Soc. 1998, 120, 5321-5322.

(19) Rose, A.; Zhu, Z.; Madigan, C. F.; Swager, T. M.; Bulovic, V. Nature 2005, 434, 876-879.

(20) McQuade, D. T.; Pullen, A. E.; Swager, T. M. Chem. Rev. 2000, 100, 2537-2574.

(21) Datar, A.; Balakrishnan, K.; Yang, X. M.; Zuo, X.; Huang, J. L.; Yen, M.; Zhao, J.; Tiede, D. M.; Zang, L. J. Phys. Chem. 2006, 110, 12327-12332.

(22) Hughes, R. E.; Hart, S. P.; Smith, D. A.; Movaghar, B.; Bushby, R. J.; Boden, N. J. Phys. Chem. B 2002, 106, 6638-6645.

(23) Hoffmann, M.; Schmidt, K.; Fritz, T.; Hasche, T.; Agranovich, V. M.; Leo, K. Chem. Phys. 2000, 258, 73-96.

(24) Cragin, J. H.; Leggett, D. C. A Report to DARPA, US Army Cold Regions Research and Engineering Laboratory July 2003, ERDC/CRREL TR-03-12.

(25) Peumans, P.; Yakimov, A.; Forrest, S. R. Journal of Applied Physics 2003, 93, 3693-3723. 